Session \#

\title{
The TeachEngineering Digital Library: Engineering Comes Alive for K-12 Youth
}

\author{
Jacquelyn F. Sullivan, Martha N. Cyr, Michael A. Mooney, René F. Reitsma, \\ Nancy C. Shaw, Malinda Schaefer Zarske and Paul A. Klenk \\ University of Colorado at Boulder, CO / Worcester Polytechnic Institute, \\ Worcester, MA / Colorado School of Mines, Golden, CO / Oregon State \\ University, Corvallis, OR / Duke University, Durham, NC / University of \\ Colorado at Boulder, CO / Duke University, Durham, NC
}

\begin{abstract}
Do you believe that technological literacy should be a component of basic literacy? Are you convinced that engineering can be used as a vehicle for integrating science and math in K-12 settings, inspiring today's youth to be the innovators of tomorrow? Do you want to incorporate advances in engineering and technology to spice up the learning of science fundamentals? Are you and your engineering students compelled to engage in K-12 engineering yet don't know where to start? Truth be told, do you dream of a searchable, online collection of classroomtested K-12 engineering lessons and hands-on activities that explore science and math in an age-appropriate, applied fashion relevant to the lives of youth? If you do not know for which math or science that fourth- or eighth-grade teacher you are working with is accountable, or if compliance with K-12 educational standards baffles you, then the TeachEngineering digital library collection was created for you!
\end{abstract}

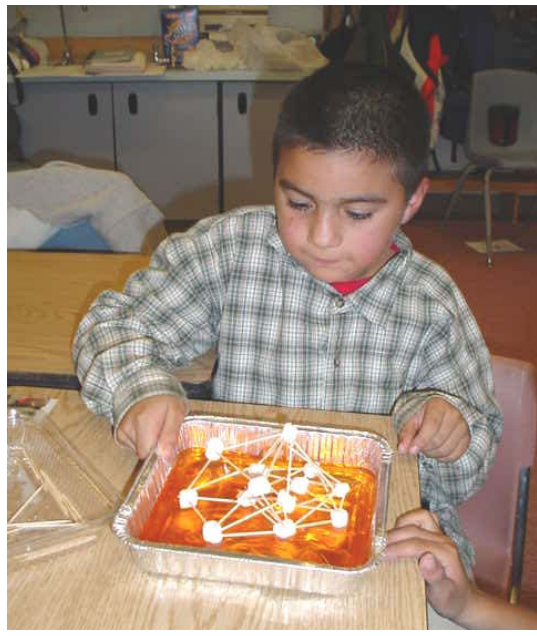

A third-grade student tests the strength of his spaghetti and toothpick structure in a fun, hands-on engineering activity.

The NSF-supported TeachEngineering digital library collection is a powerful resource for those in K-12 or higher education, industry and professional communities wanting to engage young students in the joys and creativity of an engineering future. In partnership with K-12 teachers, the initial collection was developed and classroom-tested by engineering students and faculty from four engineering colleges working on NSF GK-12 initiatives. The TeachEngineering curricula are aligned with national STEM educational standards and include quality-control criteria to ensure teacher-friendly, low-cost lessons and activities that integrate STEM concepts through engaging engineering exploration. See TeachEngineering.com. 


\section{Introduction}

The TeachEngineering digital library collection is part of NSF's National Science Digital Library (NSDL) initiative (www.nsdl.org). TeachEngineering is a searchable, web-enabled collection of standards-based K-12 engineering curricula, capitalizing on using engineering as a vehicle for teaching science and math in K-12 classrooms. The collection was released in early 2005, and includes more than 20 curricular units, more than 100 lessons and nearly 200 hands-on engineering activities developed by the partner institutions. Some of the curricular materials use "living labs," student-friendly web portals to real and archived data from real-world systems for use in math, science and engineering activities. We plan to markedly expand the collection during the next few years by including hundreds of engineering lessons and activities created by countless engineers involved in K-12 outreach nationally. Use of the TeachEngineering collection is available free of charge at TeachEngineering.com.

\section{Why K-12 Engineering?}

In a knowledge-based society, education creates the foundation for our capacity to perform, both individually and collectively. As we explore the value of engineering and technological education as early as elementary school, we approach a new frontier. We are compelled to navigate this frontier for several reasons: the poor science and math performance of our nation's youth; flat engineering enrollments nationally; under-representation of women and minority students in the engineering professions; the unflattering public perception of the role engineers play in creating new technologies and in improving our quality of life; and the need for technological literacy for all of our citizens.

In spite of soaring U.S. college enrollments in the last 25 years, the number of undergraduates completing degrees in engineering has declined dramatically after peaking in 1988, ${ }^{1}$ and is still below the number of new B.S.-level engineering graduates in $1988 .^{2}$ An engineering education creates access to a successful and rewarding career and personal future, and people from all backgrounds should have ample opportunity to share in that future.

The participation of women in engineering and technology programs has stagnated, with females accounting for fewer than $21 \%$ of B.S. engineering graduates. Sadly, as society has become more technology driven, the representation of women prepared to contribute to the technological revolution is shrinking. For instance, in 2004, girls comprised fewer than $15 \%$ of the high school students who took AP computer science exams, down from 17\% in 1999 - by far the lowest percentage of girls' participation in any AP subject tests administered in 2004 . $^{3}$

Moreover, although African American and Hispanic students comprise $30 \%$ of university student populations, they collectively accounted for fewer than $11 \%$ of 2003 B.S. engineering graduates - a lower percentage than in $1999 .^{4}$

Responding to these collective backwards trends, the demand for inclusion of engineering experiences in the K-12 setting is growing. The use of standards-based, age-appropriate engineering curricula that integrates science and math, and builds upon the wonder of hands-on, scientific inquiry, coupled with critical thinking and reasoning skills, becomes an attractive 
approach. Using engineering as a vehicle for the integration of science and mathematics promotes technological literacy and at the same time helps students understand the relevance of applied science and math in the engineering context, which so shapes the world in which they live.

The National Science Foundation's GK-12 program, initiated in the late 1990s, spawned the development and classroom testing of quality K-12 engineering curricula in more than 20 engineering colleges. From these geographically distributed, localized initiatives sprung a grassroots call to create an online, shared and evolving repository of hands-on engineering curricula so that educators - university professors and K-12 teachers alike — would be able to engage in K-12 engineering without a large resource commitment or steep learning curve.

\section{Effective K-12 Science/Math/Engineering Curriculum}

According to a rich body of literature, highly effective science and math curricula should be inquiry-based; i.e., involving the active process of asking questions, collecting and analyzing data, critical thinking, constructing new knowledge based on these answers, and problem solving. ${ }^{5,6}$ Studies conducted with science students found that inquiry-based science activities have positive effects on students' science achievement, cognitive development, laboratory skills and understanding of science content as a whole when compared with more traditional teaching approaches. ${ }^{7,8}$ Students participating in hands-on activities, performing their own science experiments learn more than those who do not. ${ }^{9,} 10$ A hands-on inquiry-based approach is particularly appealing to students with disabilities (special education), teaching them to use kinesthetic modalities, verbal modalities, pictorial representations and creativity. ${ }^{11}$ Other studies have shown that students in classrooms employing an inquiry-based approach have improved attitudes toward both science and school as opposed to more negative attitudes resulting from traditional teaching methods. ${ }^{12}$, ${ }^{13,14}$ Furthermore, Eisenhardt ${ }^{15}$ showed that change in interest results in change in achievement.

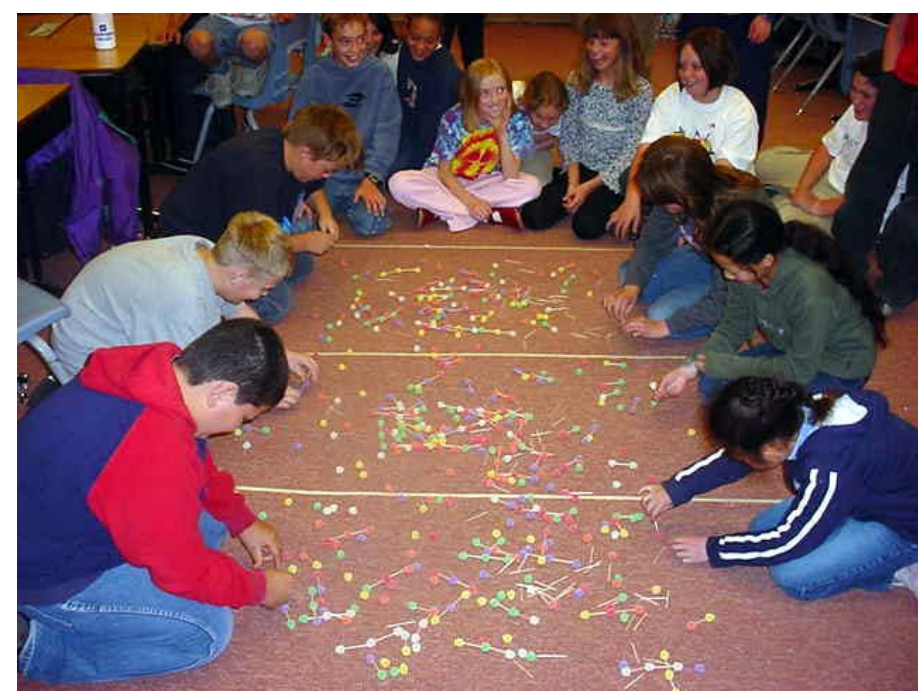

Making and destroying $\mathrm{O}_{2}$ and $\mathrm{O}_{3}$ molecules using gumdrops and toothpicks, fifth-grade students conduct an interactive ozone depletion model to explore the real-world dynamics that engineers take into consideration when designing air pollution cleanup methods.

Engineering projects taught in teams provide hands-on, inquiry-based opportunities for learning in a cooperative setting. Baker ${ }^{16}$, Meyer ${ }^{17}$, and Johnson and Johnson ${ }^{18}$, for instance, show that most female students prefer and take a more active role in creative, cooperative learning activities, whereas Kahle \& Meece ${ }^{19}$ show that hands-on, conversational curricula lead to higher retention and interest by female students. Other work has shown that African American and 
Hispanic students performed better in cooperative learning and workshop environments. ${ }^{20,21}$ The inquiry-based approach used in the TeachEngineering curricula has been demonstrated as an effective instructional method for students with disabilities, ${ }^{11}$ while the use of hands-on, projectbased learning has proven effective in educating students enrolled in ESL (English as a second language) and special education programs. ${ }^{22,23}$ Finally, research has demonstrated that improved learning occurs if the curriculum is interesting and relevant to students' lives, and promotes connection to applications and other subjects. ${ }^{5}$ Topics must be dynamic and organic, address real-world problems, and provide opportunities for extension, either in terms of meaning or significance. $^{24}$

\section{Alignment with Educational Standards}

Developing curriculum to the above criteria for effective teaching and learning is challenging. However, most K-12 teachers also face the additional challenge of being required to teach to specific educational standards. This implies that any effective K-12 curriculum must be aligned with relevant state and national standards, and must include ways to assess learning objectives and outcomes. Project- and inquiry-based hands-on curriculum may be exciting for teachers and students alike, but without ways to gauge how well the educational standards and learning objectives are met, teachers might find it difficult to justify using such curricula.

The TeachEngineering collection is comprised of inquiry-based, hands-on learning curricula mapped to educational content standards. So, in addition to a varied collection of curricular materials, the digital library also provides K-12 teachers with ways to assess learning outcomes, and aligns every curricular item with state and national educational standards.

\section{The TeachEngineering Curriculum}

The TeachEngineering digital library collection was developed as a joint initiative among faculty from five institutions of higher education and ASEE. Four of the institutions had active NSF GK12 grants that focused on helping university educators teach engineering in grades K-12. Each grant team was looking for a way to disseminate to a larger audience the K-12 engineering curricula it had developed. At the same time, ASEE was developing a K-12 focus within the society at large, and thus joined the team as the marketing partner for the collection.

While the engineering faculty brought together curricular materials that promoted hands-on K-12 engineering, we had marked differences in how our materials were structured and presented. Some institutions had created comprehensive curricular units comprised of multiple lessons and activities to be taught as integrated units; others had developed independent lessons and activities. Moreover, each had developed its own distinctive and different "branding" look for its curricular materials.

Early in the collaboration, the participating faculty spent two days solidifying their vision for an online, searchable digital library collection, initiating the concept of a joint "branding." The team readily agreed that everything in the collection should have a common look and feel for ease of use by teachers. Reaching consensus on the specifics of both content and common look and feel, however, required considerable work. 
The underlying system architecture was developed by faculty and students at Oregon State University's (OSU) College of Business, who participated in all functionality discussions about the collection. Building upon the K-12 engineering education vision, the OSU team created mechanisms for each participating engineering school to add their curricular contents to the TeachEngineering collection, created a common look and feel, provided functionality for searching and displaying items, and devised a checking system to make sure all linked connections within the collection remain operational.

A method for associating curricular materials with each other was agreed upon, with every curricular item directly or indirectly linked to one or more of 13 Subject Areas (algebra, physical science, science and technology, etc.). The collection's items are also classified as Curricular Units (themes or related topics), Lessons (focused topics; sometimes grouped into Units) or Activities (hands-on components; often associated with Lessons). To be part of the collection, each curricular item must contain certain elements; other elements are optional. Table 1 provides a summary of the required and optional elements for curricular Units, Lessons and Activities.

\section{Correlating State and National Standards}

Because the curriculum-developing faculty members were based in Colorado, Massachusetts and North Carolina, the decision was made to correlate standards between these three states and various national standards. Hence, contributors provided their curricular materials using their own state standards.

A centrally-stored cross-correlation between state and national standards helps teachers from states other than the one for which the curriculum was explicitly indexed associate the lessons or activities with broader, national sets of standards. For instance, if a lesson is indexed to Massachusetts standard 1.1, TeachEngineering's search engine finds it when someone searches for curricula related to AAAS Benchmark 3.B.1 or McREL 4.4, because of the high correlation between that Massachusetts standard and those two national standards. The correlation is a comparison of each grade level standard to the national standards for the same grade level for each state, scored on an ordinal four-point scale.

The standards correlation in TeachEngineering indexes the Mid-Continent Regional Laboratory (McREL), the AAAS Benchmarks for Science Literacy, the National Science Education Standards (NSES), the National Council of Teachers of Mathematics (NCTM) standards, and the International Technology Education Association (ITEA) Standards for Technological Literacy. 
Table 1. Required and optional curricular elements in the TeachEngineering collection.

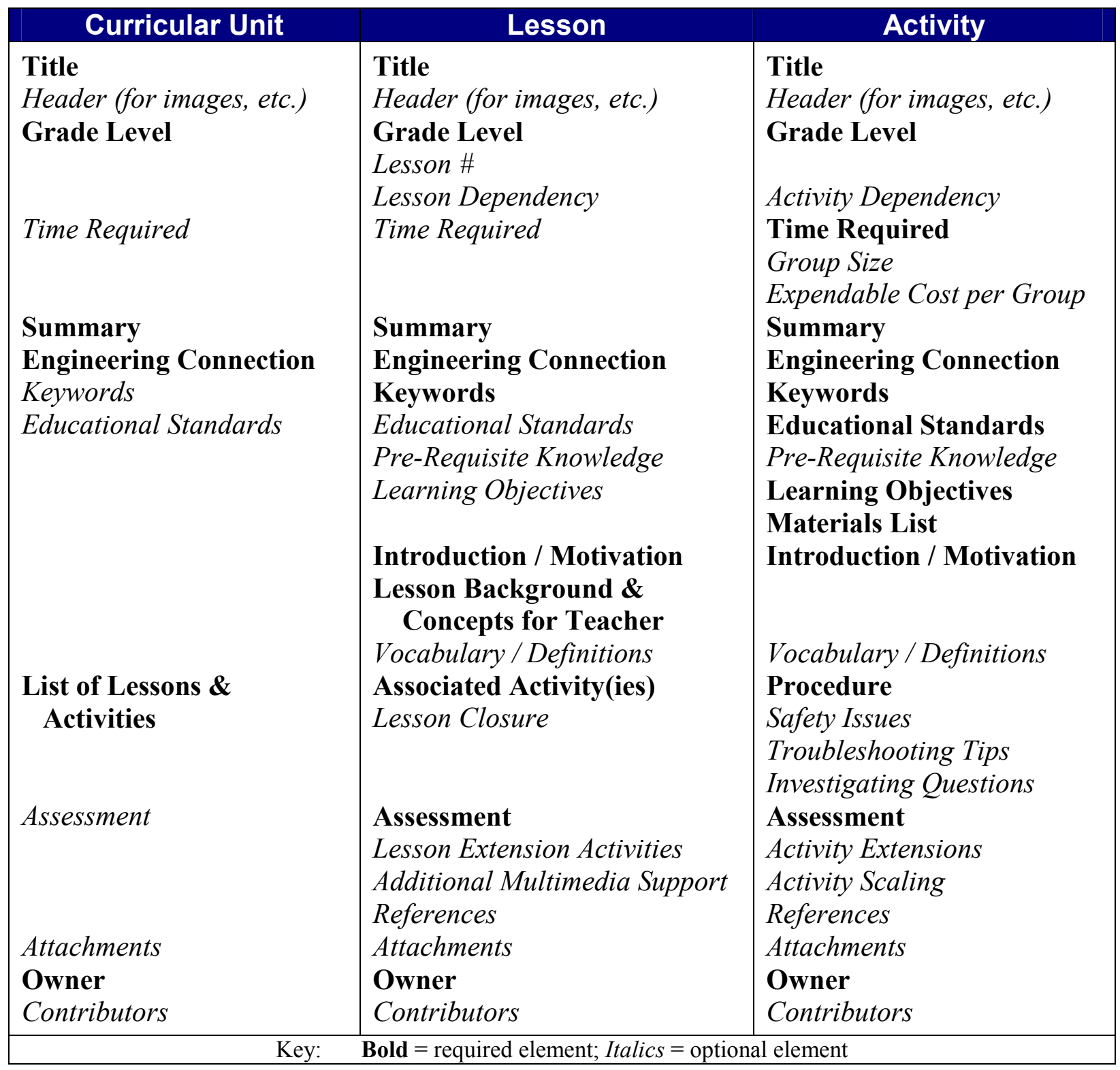

\section{TeachEngineering Infrastructure}

TeachEngineering is implemented using a traditional digital library architecture based on the well-known Linux, Apache, MySQL and PHP (LAMP) family of software tools. The following scenario briefly describes the fate and path of a TeachEngineering curricular item through the system's architecture.

1. Once the content of a curricular item is created, it is formatted using Altova's Authentic software, which stores the document in XML form. This allows for a series of internal validity and integrity checks. After the document passes all editing and formatting tests, it is uploaded to the central document repository. 
2. Once daily, a Java-based spider program "crawls" the collection, extracting information needed to support user searches of the collection. The extracted information is stored in a MySQL relational database.

3. Once daily, a PHP-based process extracts a different set of information from each document in the collection and makes it available to the outside world as metadata, or data describing the documents. These data are periodically "harvested" by digital library service providers such as cross-institutional search engines; e.g., NSDL.

4. To explore or search the collection, users point their web browser to the TeachEngineering home page to access the document search engine. The search engine, written in PHP-DOM and SQL, runs queries against the database built by the spider and returns any matches to the users' browser. A variety of searches is supported; e.g., a simple word search, or by grade level, time required, group size, expendable cost, educational standard, etc.

5. Once a user selects a document listed in the search engine's results, a request is made to the system's rendering engine, also written in PHP-DOM and SQL. This software converts the XML document into browser-displayable HTML. In the process, it queries the database for relevant information not directly stored in the document, such as the relative place of the document in a larger curricular unit. At this point, a user may log into his/her own "MyTE" personal space, for purposes of keeping track of chosen curricular materials and submitting curriculum reviews.

6. Although K-12 teachers and engineering faculty comprise the target population of

TeachEngineering users, requests to the search engine originating from programs are honored as well. These are processed through a Web service written in PHP-SOAP. Whereas typical user requests are expressed by means of interaction through a browser, web services are mediated through an exchange of XML packages.

The integrity of the collection is monitored by a set of automated, periodically-invoked quality control tools. Among these are facilities that log all user interactions with the TeachEngineering system to a central database. Through analysis of these logs, TeachEngineering use patterns can be assessed for system usability improvement.

\section{Searching the TeachEngineering Collection}

Whereas most generic digital libraries, such as Google ${ }^{\mathrm{TM}}$ or NSDL, provide collection searches based on keywords or strings (of one or more words), K-12 teachers benefit from searches that index on attributes such as grade level, educational standard, expendable cost or combinations thereof. Hence, TeachEngineering offers three interfaces for searching the collection:

1. A simple word search. This search accepts a search string (of one or more words), and looks for it in the title, summary and keywords of every curricular item.

2. An advanced search that accepts grade level, time required, group size, expendable cost, keywords or combinations thereof.

3. A search based on educational content standards. Users first choose a standards source; i.e., a state's standards or one of the national standards sets such as McREL or AAAS Benchmarks. To focus the search, additional (and optional) search criteria include the standard's subject (e.g., mathematics or science), topic (e.g., physical science or life science), specific number, or combinations thereof. 
Search results are returned in a tabular format so they may be sorted in either ascending or descending order according to the values of any of the table's columns (see example).

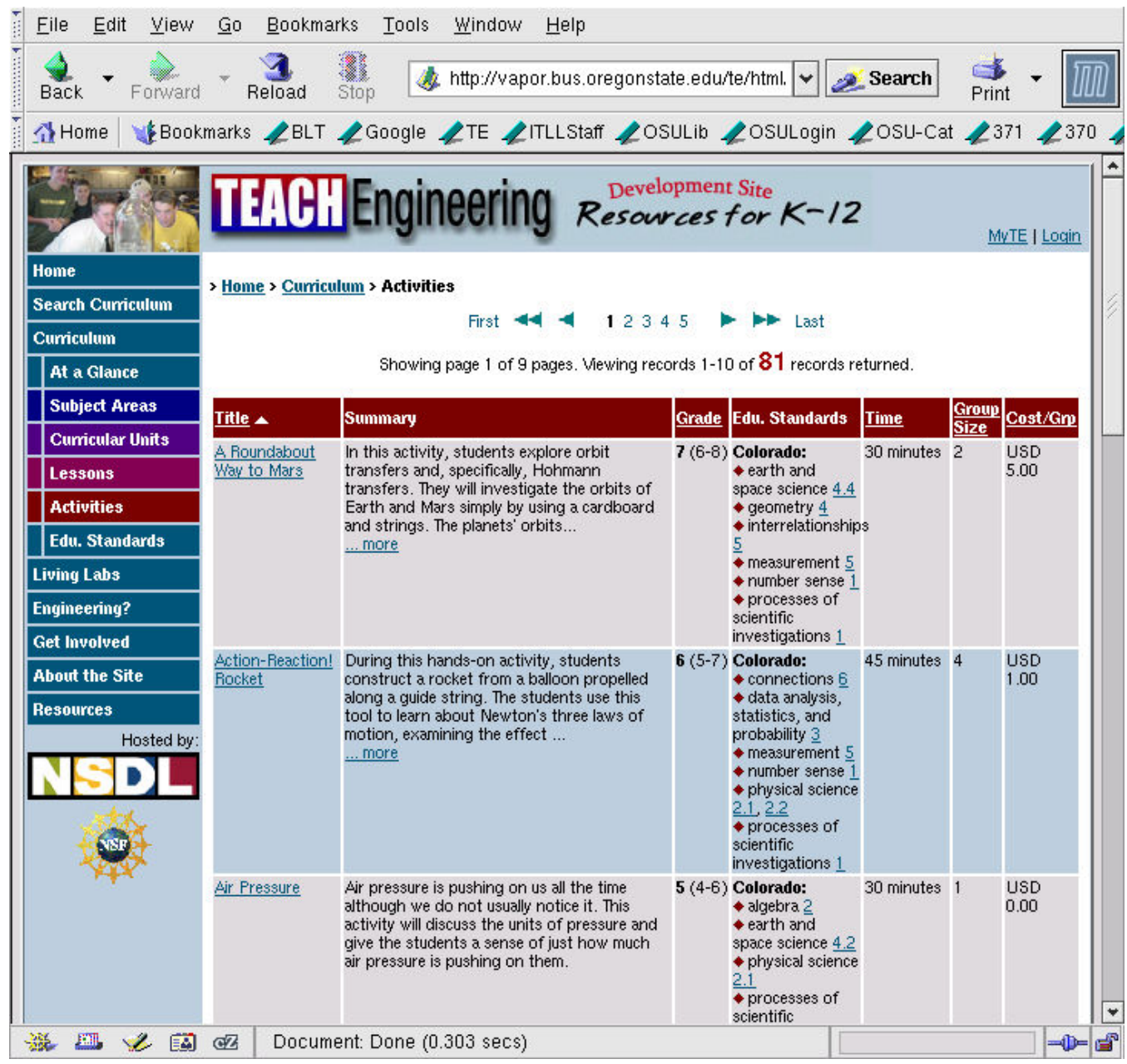

Example search results for curricula meeting Colorado science standards.

\section{Living Laboratories}

The TeachEngineering collection includes a number of "living labs" — web portals to real and archived data from real-world systems for use in math, science and engineering activities. Each living lab is constructed in a middle-to-high school, student-friendly manner. Students can immediately start working with the data or engage in guided activities provided by curricula in the TeachEngineering collection. For example, the Engineering our Water living lab is built around the rich collection of U.S. stream flow and rain gauge data maintained by the U.S. Geological Survey. The Wind Engineering living lab provides access to wind turbine data, regional anemometer data, and wind turbine and wind farm design tools.

As described earlier, effective curricula are student centric, involve inquiry and are relevant to students' lives. The aim of the living labs is to encourage students to explore, construct their own 
meaning, think critically about data, and use data to perform engineering analysis and design. The data can lead students in an unlimited number of directions, from evaluating the suitability of streams in their state for kayak racing to redesigning a city's transit schedule to minimize passenger travel time. Because living lab curricula are stored in the TeachEngineering digital library, they can be searched for in the same way as other TeachEngineering curricula. Moreover, educators are encouraged to submit their new activities that use the living labs in effective ways for inclusion in the TeachEngineering collection.

\section{Getting Involved in TeachEngineering}

The TeachEngineering digital library collection is a forum for those already engaged in K-12 engineering education as well as those just becoming interested in engineering education at the K-12 level. From university faculty to K-12 teachers to parents, the collection enables educators to increase the awareness of engineering by K-12 students. There are many ways to become involved in this dynamic and continually expanding collaboration.

K-12 Educator Involvement - K-12 teachers and students were the main catalyst for developing the TeachEngineering digital library collection. The initial curricular units, lessons and activities were developed in partnership with classroom teachers in an effort to engage and promote the science, math and technological literacy of K-12 students. One major goal of the collection is to provide K-12 educators with a rich resource of relevant and useful engineering lessons and activities for a diverse audience of students and school settings, including extracurricular programs.

K-12 teachers who desire to become involved can publish their own original engineering lessons or activities in the TeachEngineering digital library collection. Submissions may range from newly developed, fully instrumented curricular units to the addition of a hands-on activity to an existing lesson. Teachers can also rate content for value and appropriateness in the classroom. An average of all submitted review ratings is displayed on the rendered website document. This feature allows K-12 educators to let other teachers and contributors know how useful a document is, in practice. Educators may also provide input, such as making suggestions for extension activities or suggesting better standards mapping, on particular components of a lesson or activity. K-12 educators can also help advertise the collection by introducing the website to friends and colleagues.

Engineering Faculty Involvement - Engineering faculty drove the development of the TeachEngineering digital library collection and continue to play a central role in its expansion. The initial curricular units, lessons and activities in the collection were created at each of the TeachEngineering university partner institutions from materials developed under NSF GK-12 and other grants. Every teacher, teaching fellow, teaching assistant and faculty member involved with K-12 engineering outreach is encouraged to contribute engineering content to the collection. By placing engineering materials in a single searchable, web-enabled location, teachers and students alike can easily search and select from a variety of cutting-edge K-12 engineering curricula. 
The TeachEngineering consortium encourages engineering faculty to submit their own content for publication in the digital collection. Thus, engineering faculty who have not previously participated in K-12 outreach can readily communicate their research passions by creating new curricular materials that incite curiosity in the minds of youth and solidify in them a lifelong interest in learning. Faculty who desire to become involved will use curricular templates as guides for creating TeachEngineering-compliant curricular units, lessons and activities based on their own K-12 research and interests.

\section{TeachEngineering Collection Challenges}

Creation of the TeachEngineering collection positions the engineering education community to collectively make available, share and continuously improve the impressive K-12 engineering curricula that has been developed at dozens of engineering colleges. With this national distribution mechanism, already-developed K-12 engineering curricula can, for the first time, become available to the educational community at large, free of charge, and with the added advantages of a common look and feel, and consistent curricular components. However, the collection is in its infancy, and collection maintenance and expansion mechanisms are currently under development.

Continued Collection Growth - The vision for the TeachEngineering collection is that contents increase at least 10 -fold in the next three to five years, due to contributions from a broad spectrum of both engineering educators and K-12 teachers. This requires the establishment of quality assurance and quality control mechanisms to maintain high standards for the collection's content, as well as a central processing capability for newly submitted curricula.

Collection Maintenance - Collection maintenance challenges abound, and include routine upgrading of the system software, responding promptly to broken web links, and upgrading curricular components to reflect user feedback.

\section{Expanding the State Standards to Include All 50 States - As the TeachEngineering} collection grows beyond its initial base, the ability to tie the curricula to the educational standards of all states becomes critical. Understandably, teachers prefer to use the standards from their own state instead of the national ones, due to two factors: 1) national standards are a recommended set of items for a content area, but are not always adopted at the state level, and 2) state standards are the measures used for individual state testing, which will be increasingly more important when No Child Left Behind (NCLB) testing goes into full swing in 2006.

Expanding educational content standards to include all 50 states could be relatively easy if we did not desire to make TeachEngineering a national resource for teachers. Contributors from each state would simply enter their curricular content mapped against their own standards, and if someone from another state desired to use that lesson, that user would have to rely on the correlation between the original state's standards and the national standards. However, we do not consider this a practical long-term or teacher-friendly approach. We are of the opinion that for TeachEngineering to become a nationwide resource for teachers, we must have a way for the standards of one state to be correlated with those from another. This is a major task that is currently being addressed by two non-TeachEngineering groups with NSDL resource grants. We 
are coordinating with these groups and hope to pilot in TeachEngineering in the near future the standards correlation/mapping tools they develop.

State Standards Currency — In addition to cross correlations between all states, keeping the collection current with the most recent state and national educational content standards presents a challenge, as most states update or revise their standards about once every five years. For example, the static correlation table for the state standards for three states that was developed for TeachEngineering is likely to be outdated in four to five years. Although one of the standards correlation resource projects currently underway will maintain a current database of all the state standards, TeachEngineering must accommodate these changing standards.

\section{Conclusion: Creating Value for K-12 Engineering Education}

Our collective challenge as educators is to design a more seamless K-16 education that integrates science, math and engineering with the liberal arts, in which technological literacy is considered a component of basic literacy and not relegated to the tech lab. We strive to design a more relevant education that creates tomorrow's leaders, prepared for a world in which analytical decision-making is expected of policy makers and implementers at all levels.

Our national conscience is not aware of the role that engineers play in advances in medical research, in alleviating human suffering through providing safer water and cleaner air, or in creating the MP3 player that puts 5,000 tunes at our fingertips. Engineers do not like failures, and yet we have collectively failed to communicate the excitement and satisfaction of our creative profession. As engineers, we understand that innovative, technological breakthroughs are driven by the convergence of disparate disciplines. And yet, we have historically drawn unnatural distinctions between collegiate-level engineering education and the K-12 educational experiences that drive both the preparation and the passion of youngsters to pursue engineering futures.

Engineering educators have long lamented that the "pipeline" into the engineering profession has too many leaks. With the resources of the TeachEngineering digital library we can now collectively move to action. The curricular resources in the collection - envisioned to grow dramatically in the next few years - provide wide-ranging opportunities for engineering educators and students to partner with local K-12 teachers to use hands-on, inquiry-based engineering content to cement the science and math fundamentals for which teachers are already accountable, and promote technological literacy for youth through the exploration of high quality, standards-based K-12 engineering curricula that has been classroom tested and designed for teachers.

The TeachEngineering collection provides educators from all walks of life with easy-to-use, searchable, hands-on engineering curricula and portals to "living labs" that integrate science and math concepts via the exploration of engineering. The lessons and activities relate to everyday encounters in the lives of youth, thus providing a powerful applications-based context for student learning. We invite you to learn how to use the collection to meet the needs of your community, and contribute your K-12 engineering curricula to expand the TeachEngineering collection. 


\section{Acknowledgements}

Partners in this National Science Digital Library project include the University of Colorado at Boulder, Worcester Polytechnic Institute, Colorado School of Mines, Duke University, Oregon State University and ASEE. Creation of this collection is funded by the National Science Foundation's National Science, Technology, Engineering, and Mathematics Education Digital Library (NSDL) program under grant no. 0226322, the Daniels Fund and the partnering universities. The contents for the TeachEngineering collection were initially created under several NSF GK-12 grants and a U.S. Department of Education FIPSE grant no. P116B010922.

The authors gratefully thank the dozens of graduate and undergraduate engineering Fellows who contributed content and creativity to the TeachEngineering collection over many years. We also thank Denise Carlson and Janet Yowell for their contributions to curricular template design, interface aesthetics and contents editing; Bobby Rinehart, Jodi Kiefer and Chris Baker for their contributions to developing the "living labs" framework; Beth Myers for resolving myriad uploading and tagging issues; Nicole Davis for her contribution to standards correlation; and Denise Carlson for editing this manuscript. Lastly, an incredible team of undergraduate students in the OSU College of Business contributed to the creation of the system infrastructure.

\section{Bibliographic Information}

1 National Science Board. "Chapter 4. Higher Education in Science and Education." Science and Engineering Indicators. Arlington, VA: National Science Foundation, 2000.

2 Gibbons, M.T. "Engineering on the Rise." ASEE Profiles of Engineering and Engineering Technology Colleges, 2002 Edition. www.asee.org: American Society for Engineering Education, 2003.

3 "Summary Reports: 2004, National Report." The College Board. n.d. Accessed December 21, 2004. < http://www.collegeboard.com/student/testing/ap/exgrd_sum/2004.html >.

4 Gibbons, M.T. "Databytes.” PRISM Magazine, American Society for Engineering Education, 14(1), September 2004, pp. 20-21.

5 National Research Council. National Science Education Standards. Washington, DC: National Academy Press, 1996.

6 American Association for Advancement of Science. Science for All Americans: Project 2061. New York, NY: Oxford University Press, 1989.

7 Chang, C.Y and Mao, S.L. "The Effects of an Inquiry-Based Instructional Method on Earth Science Students' Achievement.” ERIC Document Reproduction Service No. ED 418858, 1998.

8 Ertepinar, H. and Geban, O. "Effect of Instruction Supplied with the Investigative-Oriented Laboratory Approach on Achievement in a Science Course.” Educational Research, 1996, 38, pp. 333-344.

9 Burkam, D.T., Lee, V.T. and Smerdon, B.A. "Gender and Science Learning Early in High School: Subject Matter and Laboratory Experiences." American Educational Research J., 1997, 34, pp. 297-331.

10 Freedman, M.P. "Relationships among Laboratory Instruction, Attitudes toward Science, and Achievement in Science Knowledge.” J. Research in Science Teaching, 1997, 34, pp. 343-357.

11 Mastropieri, M.A., Scruggs, T.E. and Magnusen, M. "Activities-Oriented Science Instruction for Students with Disabilities.” Learning Disability Quarterly, 1999, 22, pp. 240-249.

12 Gibson, H.L. "Case Studies of an Inquiry-Based Science Programs' Impact on Students' Attitudes towards Science and Interest in Science Careers.” ERIC Document Reproduction Service No. ED 417980, 1998.

13 Shrigley, R.L. "Attitudes and Behavior Correlates." J. Research in Science Teaching. 1990, 27(2), pp. 97-113. 
14 Mooney, M.A. and Laubach, T. "Adventure Engineering: A Design Centered, Inquiry Based Approach to Middle Grade Science and Mathematics Education." J. Engineering Education, American Society for Engineering Education, 2002, 91(3), pp. 309-318.

15 Eisenhardt, W.B. "A Search for the Predominant Causal Sequence in the Interrelationship of Interest in Academic Achievement. A Cross-Legged Panel Correlation Study." Doctoral dissertation, Duke University, 1976. Dissertation Abstract International, 1997, 37, 4225A.

16 Baker, D. "Gender Differences in Science: Where They Start and Where They Go." Meeting of the National Association for Science Teaching and Research, April 1990.

17 Meyer, K. "Reflections on Being Female in School Science: Toward a Praxis of Teaching Science." J. Research in Science Teaching, 1998, 35, pp. 463-471.

18 Johnson, R.T. and Johnson, D.W. "Cooperative Learning and the Achievement and Socialization Crisis in Science and Math Classroom." In A.B. Champagne and L.E. Horning (Eds.) Students and Science Learning. Washington, DC: American Association for the Advancement of Science, 1998.

19 Kahle, J.B. and Meece, J. "Research on Gender Issues in the Classroom." In D.L. Gable (Ed.) Handbook of Research on Science Teaching and Learning. New York, NY: Macmillan Publishing Co., 1994, pp. 542-557.

20 Atwater, M.M. "Research on Cultural Diversity in the Classroom." In D.L. Gable (Ed.) Handbook of Research on Science Teaching and Learning. New York, NY: Macmillan Publishing Co., 1994, pp. 558-576.

21 Bonangue, M.V. "Long Term Effectiveness of the Calculus Workshop Model." A presentation as part of Increasing Minority Participation in Math-Based Disciplines, a Chautauqua Shortcourse, University Extension Services, California State University, Long Beach, April 1992.

22 Gersten, R. and Baker, S. "What We Know about Effective Instructional Practices for English-Language Learners." Exceptional Children, 2000, 66(4), pp. 454-470.

23 Kame'enui, E.J., Carnine, D.W., Dixon, R.C., Simmons, D.C. and Coyne, M.D. Effective Teaching Strategies that Accommodate Diverse Learners. Upper Saddle River, NJ: Pearson Education Inc., 2002.

24 Hurd, P.D. Inventing Science Education for the New Millennium. New York, NY: Teacher College Press, 1997.

\section{Biographical Information}

JACQUELYN F. SULLIVAN is founding co-director of the Integrated Teaching and Learning Program at the University of Colorado at Boulder's College of Engineering. She received her Ph.D. in environmental health physics and toxicology from Purdue University and held leadership positions in the energy and software industries for 13 years. She founded the extensive ITL K-12 Engineering Initiative in 1997 and has led the TeachEngineering project.

MARTHA N. CYR is the director of K-12 outreach and an adjunct professor with the Mechanical Engineering Department at Worcester Polytechnic Institute. Her main area of interest is effective engineering education for all ages. Dr. Cyr received her B.S. in mechanical engineering from the University of New Hampshire in 1982, and her M.S. and Ph. D. in mechanical engineering from Worcester Polytechnic Institute in 1987 and 1997.

MICHAEL A. MOONEY is an associate professor in the Division of Engineering at Colorado School of Mines, where he teaches civil/geotechnical engineering courses and conducts research in intelligent geosystems. Mike received a Ph.D. from Northwestern University in civil engineering in 1996. He created the Adventure Engineering curriculum and outreach program in 1999, and leads the "living lab" development for the TeachEngineering project.

RENÉ F. REITSMA is an associate professor of Information Systems at Oregon State University's College of Business. He and his students are responsible for the design, development and maintenance of the TeachEngineering system architecture. Reitsma brought 10 years of product-driven software design and development expertise to the TeachEngineering team.

NANCY C. SHAW is the director of NC Project Lead the Way (PLTW), a national pre-engineering program for junior engineers in middle and high schools. The North Carolina PLTW program is affiliated with the Pratt School of Engineering at Duke University. She received a B.S. in electrical and computer engineering from North Carolina State University, and is currently working on a graduate degree in genetics at University of North Carolina. 
MALINDA SCHAEFER ZARSKE is the curriculum outreach coordinator for the Integrated Teaching and Learning Program's K-12 Engineering Initiative at the University of Colorado at Boulder. A former middle and high school math and science teacher, she received her M.A.T. in secondary science from Johns Hopkins University and her M.S. in civil engineering from the University of Colorado at Boulder.

PAUL A. KLENK is a doctoral student in mechanical engineering and materials science at Duke University's Pratt School of Engineering where he received a B.S.E. degree in 2001 . He is in his fourth year as a graduate student coordinator for the Techtronics After-School Program at Rogers Herr Middle School. In addition to his K-12 outreach work, he is researching novel therapeutic radiation delivery methods for cancer treatment. 